\title{
Recurrent postauricular dermoid cyst: A case report
}

\author{
Rachana Tiwari, Vaishali Sangole
}

\begin{abstract}
Introduction: Dermoid cysts are congenital anomalies that arise from trapped pouches of the ectoderm near the normal fold or from the surface that has failed to separate from the neural tube. Dermoid cysts are very rare in head and neck area and its presence in postauricular region is further exceptionally rare. Only a few cases have been reported. In this study, a rare case of recurrent dermoid cyst located behind the ear with abnormal gradual growth over several years is reported which to the best of our knowledge has not been reported earlier. Case Report: A 18-year-old female presented with a swelling in the right postauricular area since six years. This swelling underwent excision six years back. Examination showed a solitary,

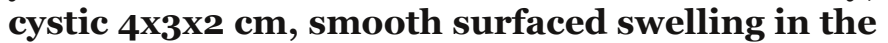
right postauricular area with a $2 \mathrm{~cm}$ ill-defined scar at the center. Ultrasonography was suggestive of a benign lesion. Fine needle aspiration cytology showed infected epidermal cyst with chronic inflammation. Through the postauricular incision an encapsulated cystic structure with embryonal cells was excised. Conclusion: Patient sought medical advice in our case for the cosmetic reason because of the
\end{abstract}

Rachana Tiwari ${ }^{1}$, Vaishali Sangole ${ }^{2}$

Affiliations: ${ }^{1}$ Tutor, Department of ENT, Mahatma Gandhi Mission Medical College \& Hospital, Kamothe, Navi Mumbai; ${ }^{2}$ Associate Professor, Department of ENT, Mahatma Gandhi Mission Medical College \& Hospital, Kamothe, Navi Mumbai

Corresponding Author: Dr. Vaishali Sangole, Kesar Garden, IRIS-1203, Kharghar, Sector-20, Kharghar, Navi Mumbai - 410210; Telephone No: (R) 022-27749688, Mobile: 9833322407; Email: vssangole@rediffmail.com

Published: 01 August 2013 embarrassing look of the prominent unilateral ear. Her concern to avoid getting a recurrence besides cosmetic correction was successfully taken care of in our case.

Keywords: Dermoid cyst, Postauricular cyst, Congenital dermoid, Recurrent dermoid cyst

$$
* * * * * * * * *
$$

Tiwari R, Sangole V. Recurrent postauricular dermoid cyst: A case report. International Journal of Case Reports and Images 2013;4(8):415-418.

$$
* * * * * * * * *
$$

doi:10.5348/ijcri-2013-08-345-CR-4

\section{INTRODUCTION}

Dermoid cysts are a type of teratoma occurring as a result of the sequestration of the skin along the lines of embryonic closure. Dermoid cysts are very rare in head and neck area, an estimated $7 \%$ of all dermoids [1]. In the classic work by New and Erich, $49.5 \%$ of head and neck dermoids were located in the orbit and no lesions were specifically identified in the ear [2]. Its presence in the postauricular area is exceptionally rare. Dermoid cysts can recur, if not completely excised. We report a case of recurrent postauricular dermoid cyst in a 18year-old female.

\section{CASE REPORT}

A 18-year-old female presented to the ENT services of our outpatient department at MGM Medical College, Kamothe, Navi Mumbai with complaint of swelling in the right postauricular area since six years (Figure 1). It was gradual in onset, progressed from a peanut size to 
the present size and was painless. There was no history of trauma, discharge from the swelling, discharging ear, decreased hearing or associated congenital anomaly. There were no constitutional symptoms. There was no history of such lesion in her family members. However, there was a similar swelling at the same site noticed since her childhood by her parents. This swelling underwent excision six years back before the recent presentation. The patient did not retain any documents related with the surgical intervention but mentioned about existence of hair tissue in the excised specimen.

On local examination a solitary, cystic, dumb-bell

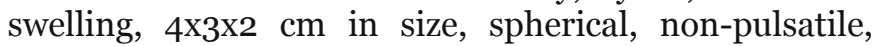
extending from the highest attachment of the pinna to $2 \mathrm{~cm}$ above the mastoid tip with smooth surface, obliterating the retroauricular sulcus with a $2-\mathrm{cm}$ horizontal ill-defined scar mark in the center of the swelling (Figure 2). There was no discharging sinus or pointing abscess. On palpation, the swelling was non tender, cystic in consistency, fluctuant, nontransilluminant, non-reducible with well defined margins. The overlying and surrounding skin was normal with no fistula or signs of infection. Bruit or any pulsation was not present over the swelling. The external auditory canal and tympanic membrane were normal. There was no evidence of facial paresis, facial asymmetry or ocular findings. A clinical differential diagnosis of a sebaceous cyst, lipoma, lymph node, inclusion dermoid, simple cyst was kept.

Ultrasonography revealed a soild, hyperechoic, well defined lesion of size $2.9 \times 2.4 \times 1.5 \mathrm{~cm}$ with no vascularity or underlying bone erosion. The features were more in favor of a benign lesion. Fine needle aspiration cytology of the swelling done after seven days coverage of antibiotics was suggestive of infected epidermal cyst. The infection was dominance of the chronic inflammation.

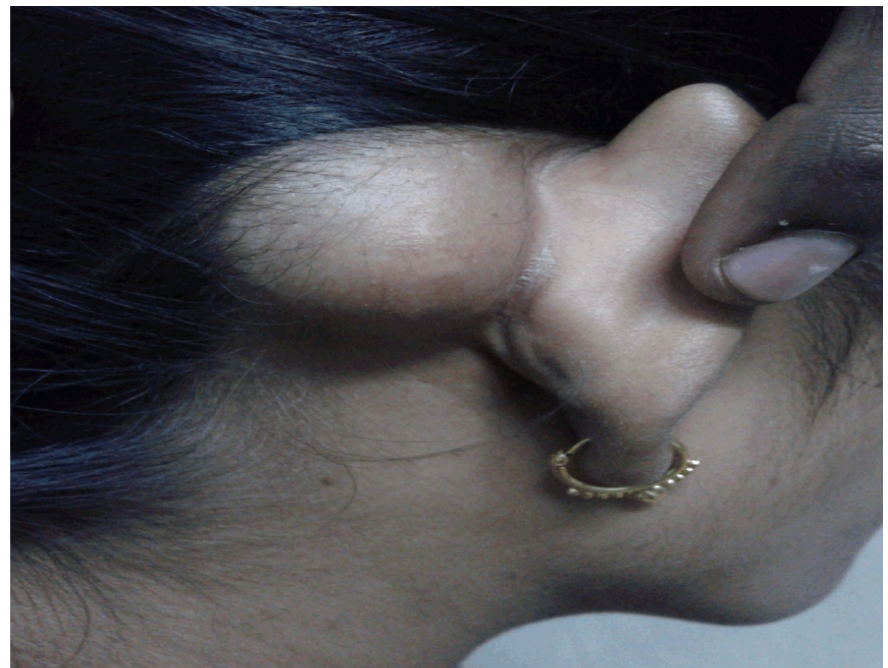

Figure 1: Clinical photograph of a 18-year-old female showing a solitary, cystic swelling, $4 \times 3 \times 2 \mathrm{~cm}$ in size, spherical,nonpulsatile,extending from the highest attachment of the pinna to $2 \mathrm{~cm}$ above the mastoid tip with smooth surface ,obliterating the retroauricular sulcus with a $2 \mathrm{~cm}$ vertical scar mark in the center of the swelling was found.

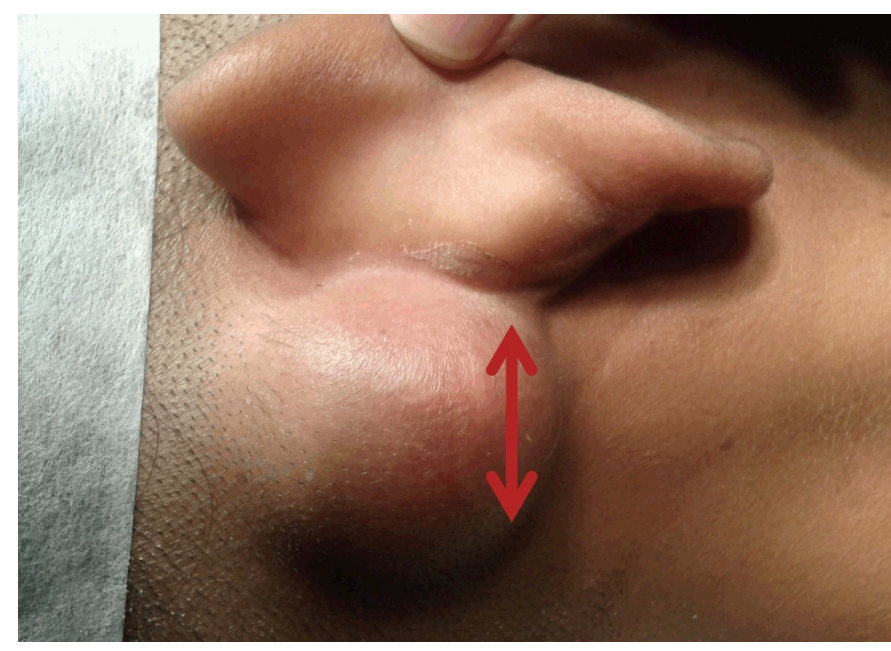

Figure 2: Photograph showing $2 \mathrm{~cm}$ horizontal ill-defined scar in the center of the swelling.

Considering the case to be recurrent due to incomplete initial removal at the first surgical attempt and the dumb-bell shaped appearance of the mass a contrast computed tomography scan of the right temporal bone was adviced. But in our country due to financial constraints of the patient the benefit of this investigation choice for knowing the extent and bony breach could not be gained.

The patient underwent surgical excision of the lesion via a postauricular incision. Intraoperative findings were that of $3 \mathrm{~cm}$ well encapsulated cystic structure containing yellowish putty oily debris with bunch of hairs inside (Figures 3 and 4). There was no connection with the external auditory canal, middle ear, or any

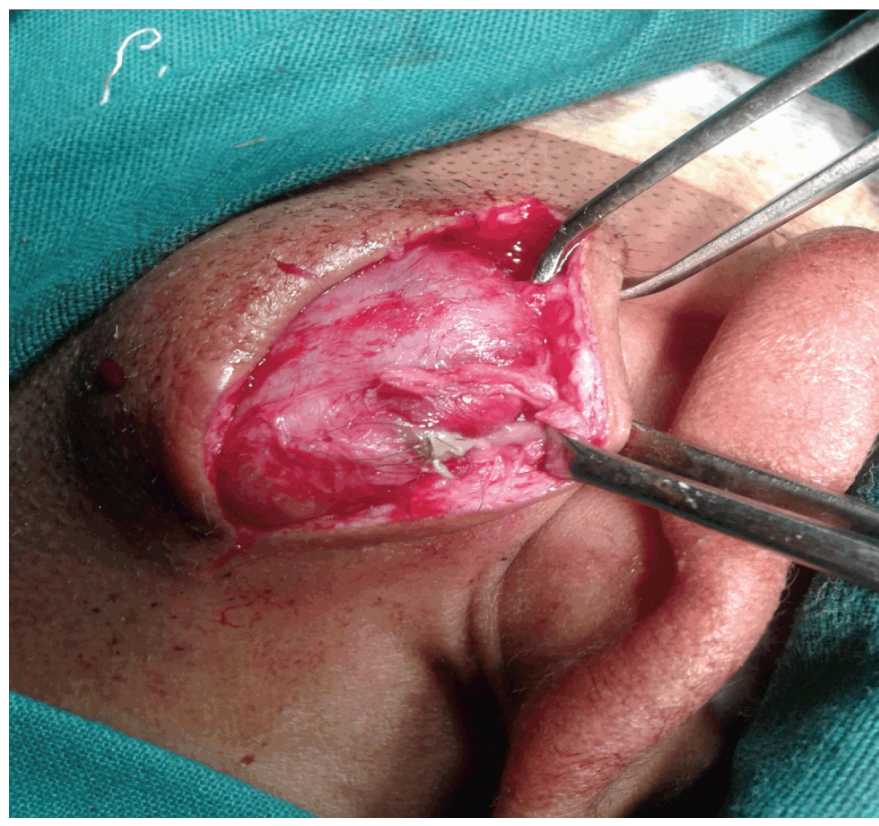

Figure 3: A 3-cm well encapsulated cystic structure containing yellowish putty oily debris with bunch of hairs inside. There was no connection with the external auditory canal, middle ear, or any intracranial extension. 
intracranial extension. The cyst was excised whole, and the defect closed primarily. The patient's postoperative recovery was uneventful.

Histopathology of the cyst indicated the diagnosis of dermoid cyst, which was confirmed on microscopic examination by the presence of keratinized stratified squamous epithelium, sebaceous glands and hair follicles (Figure 5).

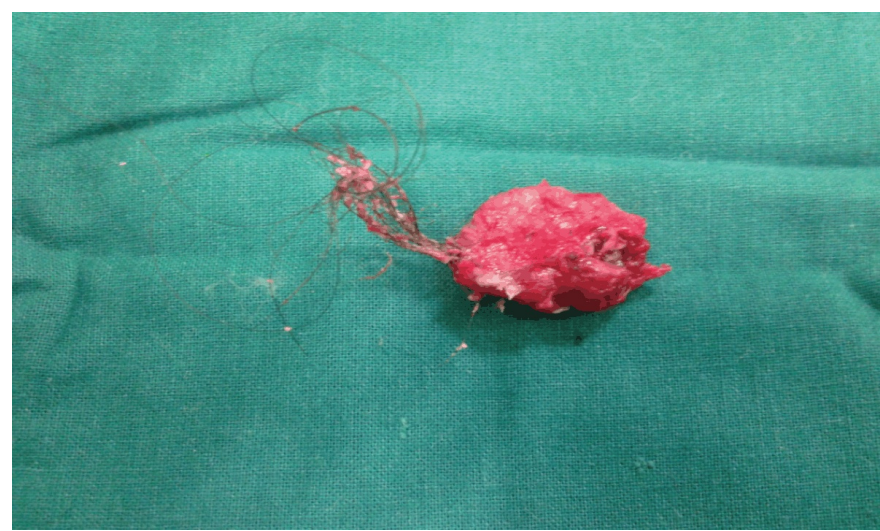

Figure 4: A 3-cm well encapsulated cystic structure containing yellowish putty oily debris with bunch of hairs inside.

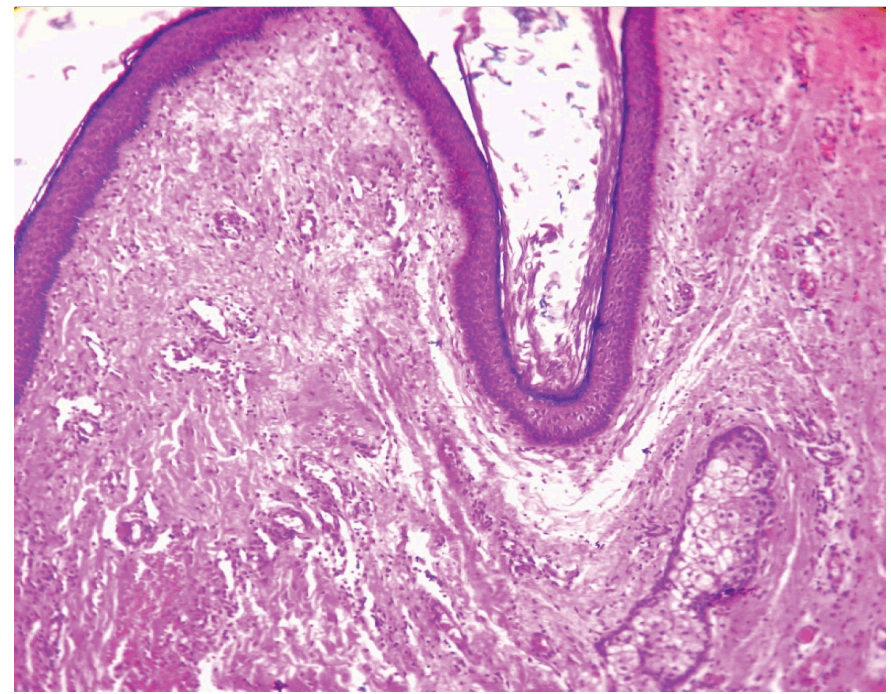

Figure 5: Histopathology showing the presence of keratinized stratified squamous epithelium, sebaceous glands and hair follicles confirming the diagnosis of dermoid cyst (H\&E stain, $\mathrm{x} 100)$.

\section{DISCUSSION}

The term dermoid cyst neither appear to be restricted to a single kind of lesion nor it is used in only a single medical discipline. The term dermoid cyst can be found in the vocabulary of dermatologists, otolaryngologists, general pathologists, gynecologists, neurosurgeons, or pediatricians. If asked, all of these clinicians would most probably define and describe dermoid cysts differently. For most dermoid cyst means subcutaneous cysts, which are usually congenital.
In reference to nomenclature, Batsakis has defined a dermoid cyst as "an epithelial lined cavity with variable numbers of skin appendages (hair, follicles, sebaceous glands, etc.)" [3]. Earlier pathology sources had more generally categorized these as being of ectodermal and mesodermal origin.

The parthenogenic theory for its pathogenesis suggests that dermoid cysts take their origin from primordial germ cells. They are postulated to originate from the congenital inclusion of germ layers in the deeper tissues along the lines on embryonic fusion. Meagher et al. suggest the cause for the bilateral prominent ears due to dermoid cyst is multifactorial with certain strong familial predilections [8].

Dermoid cysts can be divided into three types according to their histological characteristics; namely epidermoid, dermoid and teratoid. These congenital hamartomas occur with an incidence of 1 in 4,000 births, 6 times greater in females.

The cyst can exist anywhere but commonly is seen in the midline of the body. The majority of dermoid cysts arise in the ovaries. In a review of 1495 dermoid cysts collected over 25 years at the Mayo clinic, orbital lesions were found in $49.5 \%$, nasal lesions in $12.6 \%$, submental or sublingual in $23.3 \%$ and variously placed in the occipital, frontal, cervical, soft palatal and lip regions in $14.6 \%$ [2]. Those occurring in the cervicofacial region are uncommon accounting for about $7 \%$ of all dermoids [1]. One of the uncommon areas dermoid cysts are seen is the temporal area (postauricular skin, the middle ear or, even rare on the eustachian tube). They have also been reported in the auricle, middle ear and in the auriculotemporal area [4-6].

Dermoid cysts around the auricular region are rare, whereas those located in the postauricular area are extremely rare. To the best of our knowledge, there have been very few cases of postauricular dermoid cyst described in literature [1, 6-9].

In Korea, only three cases of postauricular dermoid cysts have been reported in the past. Moon et al. [10] further described a single case in 2005 and Sung et al. [11] described three cases of dermoid cysts of the auriculotemporal area in Korea in 2009. Pankaj et al. [12] described a case of unilateral postauricular dermoid cyst in an 18-year-old boy in 2007 in India. Ho et al. [13] and Mohammad et al. [14], reported a postauricular lump recently in 2011.

Our case is the rarest, first documented case of a recurrent postauricular dermoid cyst after a thorough Medline search.

\section{CONCLUSION}

Patients with postauricular dermoid cysts usually seek medical advice for the cosmetic reasons because of the embarrassing look of the prominent unilateral or bilateral ears. The patient's concern in our case was to avoid getting a recurrence besides cosmetic correction of the postauricular swelling. Sometimes complete excision is not practical if in a dumb-bell configuration 
where the cyst extends through a suture line in the skull. We could achieve both the cosmetic and recurrence aspects of concerns of the patient satisfactorily.

\section{Author Contributions}

Rachana Tiwari - Substantial contributions to conception and design, Acquisition of data, Analysis and interpretation of data, Drafting the article, Revising it critically for important intellectual content, Final approval of the version to be published

Vaishali Sangole - Analysis and interpretation of data, Drafting the article, Revising it critically for important intellectual content, Final approval of the version to be published

\section{Guarantor}

The corresponding author is the guarantor of submission.

\section{Conflict of Interest}

Authors declare no conflict of interest.

\section{Copyright}

(C) Rachana Tiwari et al. 2013; This article is distributed under the terms of Creative Commons attribution 3.0 License which permits unrestricted use, distribution and reproduction in any means provided the original authors and original publisher are properly credited. (Please see www.ijcasereportsandimages.com/copyright-policy.php for more information.)

\section{REFERENCES}

1. De Souza BA, Dey C, Carven N. A rare case of dermoid cyst behind the ear. Plast Reconstr Surg 2003 Dec;112(7):1972.
2. New GB, Erich JB. Dermoid cysts of the head and neck. Surg Gynecol Obstet 1936;65:48-55.

3. Batsakis JG. Tumors of the Head and Neck, 2nd ed. baltimore.Williams and Wilkins, 1979:227-8.

4. Ikeda M, Muto J, Omachi S. Dermoid cyst of the auricle: report of two cases. Auris Nasus Larynx 1990;16(4):193-7.

5. Minatogawa T, Node MN, Fakuda I, Kumoi T. Dermoid cyst in the middle ear. J Laryngol Otol 1993;107(4):335-8.

6. Samper A, Ruiz de Erenchun R, Yeste L, Bazan A. Dermoid cyst on the auriculotemporal area. Plast Reconstr Surg 2000;106(4):947-8.

7. Bauer DJ, Diwan R, Honig BK, Yokel B. Large asymptomatic mass on the ear. Dermoid cyst of the auricle. Arch Dermatol 1994;130(7):913-4, 916-7.

8. Meagher PJ, Morrison WA. An unusual presentation of bilateral prominent ears. $\mathrm{Br} \mathrm{J}$ Plast Surg 2001;54(4):366-7.

9. Akguner M, Karaca C, Kurtoglu B, Menderes A, Karatas O. Postauricular dermoid cyst: a case report. Eur J plast Surg 1996;19:332.

10. Moon IH, Lee WH, Joo JB, Cho JE. A case of postauricular dermoid cyst. Korean J Otolaryngology-Head Neck Surgery 2005;48(10):1294-6.

11. Sung HB, Ji WH. Three cases of dermoid cysts of auriculotemporal area. Korean J OtolaryngologyHead Neck Surgery 2009;52(5):464-7.

12. Pankaj S, Shalini S. Post auricular dermoid cyst:A case report with review of literature. The Internet Journal of Plastic Surgery 2007:4(1).

13. Ho SY, Shim T, Phang PY, Lee SJ. Postauricular dermoid cyst- a rare lump behind the ear. Eur J plast Surg 2011;34:409-11.

14. Mohammad BR, Saadat M, Nazanin ON, Armin E. Postauricular dermoid cyst. A case report. $\mathrm{J}$ of Isfahan Medical School 2011:29(150).
Access full text article on other devices

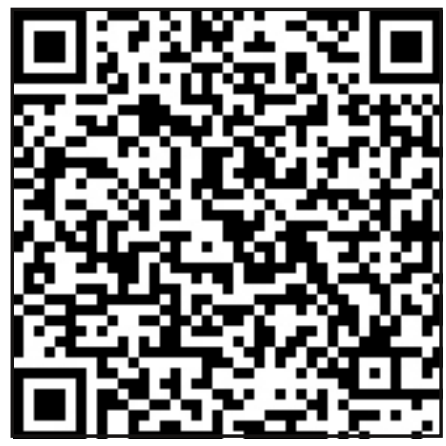

Access PDF of article on other devices

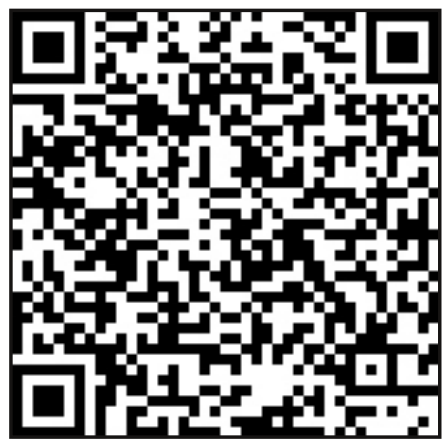

